\title{
Real-time PCR in Food Science: Introduction
}

\author{
David Rodríguez-Lázaro*1 and Marta Hernández² \\ ${ }^{1}$ Microbiology Section, University of Burgos, Burgos, Spain \\ ${ }^{2}$ Instituto Tecnológico Agrario de Castilla y León (ITACyL), \\ Valladolid, Spain
}

\begin{abstract}
Food safety and quality control programmes are increasingly applied throughout the production food chain in order to guarantee added value products as well as to minimize the risk of infection for the consumer. The development of real-time PCR has represented one of the most significant advances in food diagnostics as it provides rapid, reliable and quantitative results. These aspects become increasingly important for the agricultural and food industry. Different strategies for real-time PCR diagnostics have been developed including unspecific detection independent of the target sequence using fluorescent dyes such as SYBR Green, or by sequence-specific fluorescent oligonucleotide probes such as TaqMan probes or molecular beacons.
\end{abstract}

\section{Introduction}

Kleppe et al. described the principles of polymerase chain reaction (PCR) for first time in 1971 (Kleppe et al., 1971). But it was in 1985, with the introduction of a thermostable DNA polymerase, that Saiki and collaborators working in Cetus Corporation published the first experimental data using this technique (Saiki et al., 1985, 1988; Mullis et al., 1986). The discovery of PCR is attributed to a collaborator of Saiki, Kary B. Mullis, winner of the Nobel Prize in Chemistry in 1993. Since then, PCR has been used in more than 300,000 scientific publications (search 'PCR' in pubmed.com). This technique has been applied in different areas due to its versatility, specificity and sensitivity. Accordingly, PCR has been successfully used for microorganism identification (Rodríguez-Lázaro et al., 2007; Rodríguez-Lázaro, 2013), for the detection of ingredients of food products (Hernandez et al., 2005) and different animal and fish species (Chisholm et al., 2005; Rodríguez-Lázaro, 2013).

\section{The principle of $P C R$}

PCR is a simple, versatile, sensitive, specific and reproducible assay (Saiki et al., 1988; Cha et al., 1993). It consists of an exponential amplification of a DNA fragment, and its principle is based on the mechanism of DNA replication in vivo: dsDNA is denatured to ssDNA, duplicated, and this process is repeated along the reaction according to the following formula (Higuchi et al., 1993; Innis et al., 1999).

$$
C=C_{0}(1+E)^{n}
$$

where $C$ is the final amount of DNA, $C_{0}$ is the initial amount of DNA, $E$ is efficiency $\left(E=10^{-1 / s}-1\right.$;

\footnotetext{
*Corresponding author: Email: drlazaro@ubu.es
}

if $E=1$ then $s=-3.3219), n$ is the number of cycles and $s$ is the slope of the exponential phase.

During the denaturation step, the dsDNA melts opening up to ssDNA, and all enzymatic reactions stop (i.e. the extension from a previous cycle). To DNA denaturation, the temperature is usually raised to $93-96^{\circ} \mathrm{C}$, breaking the $\mathrm{H}$-bonds and thus increasing the number of non-paired bases. The temperature at which half of the dsDNA is single-stranded is known as the melting temperature, $T_{\mathrm{m}}$. The type of solvent, the salt concentration and the $\mathrm{pH}$ influence the denaturation process. The concentration of $\mathrm{G} / \mathrm{C}$ and T/A can also affect the $T_{\mathrm{m}}$ value. G/C-rich DNA sequences have higher $T_{\mathrm{m}}$ values compared with those T/A rich. The second phase, i.e. annealing of primers to ssDNA, takes place at temperatures closer to their $T_{\mathrm{m}}$ (usually $\left.55-65^{\circ} \mathrm{C}\right)$ and is named as temperature of annealing $\left(T_{\mathrm{a}}\right)$. The oligonucleotides used as primers typically consist of relatively short sequences (15-25nt) complementary to recognition sites, flanking the segment of target DNA to be amplified. Once the temperature is reduced, the two complementary ssDNA chains tend to rehybridize into a dsDNA molecule. In this phase, ionic bonds are constantly formed and broken between the single-stranded primer and the single-stranded template. If primers adequately anneal to the template, the ionic bond is strong enough between the template and the primer to stabilize the nascent double stranded structure and allow the polymerase to attach and begin copying the template. The extension phase is carried out across the target sequence by using a heat-stable DNA polymerase in the presence of dNTPs and $\mathrm{MgCl}_{2}$, resulting in a duplication of the starting target material. This enzyme has $5^{\prime} \rightarrow 3^{\prime}$ DNA polymerase activity, i.e. it adds dNTPs from $5^{\prime}$ to $3^{\prime}$, reading the template from $3^{\prime}$ to $5^{\prime}$. When the primers have been extended a few bases, they posses a stronger ionic attraction to the template, which reduces the probability of unbinding. The duration of the extension step can be increased if the region of DNA to be amplified is long (>1000 bp); however, for the majority of PCR experiments 1 min is sufficient to get a complete extension.

After each cycle, the newly synthesized DNA strands can serve as template in the next cycle. As shown in Figure 1, the major product of this exponential reaction is a segment of ds-DNA whose termini are defined by the $5^{\prime}$ termini of the 2 primers and whose length is defined by the distance between the primers. The products of a successful first round of amplification are heterogeneously sized DNA molecules, whose lengths may exceed the distance between the binding sites of the two primers. In the second round, these molecules generate DNA strands of defined length that will accumulate in an exponential fashion in later rounds of amplification and will form the dominant products of the reaction.

Thus, amplification, as a final number of copies of the target sequence, is expressed by the following equation:

$$
\left(2^{n}-2 n\right) x
$$

where $n$ is the number of cycles, $2 n$ is the first product 


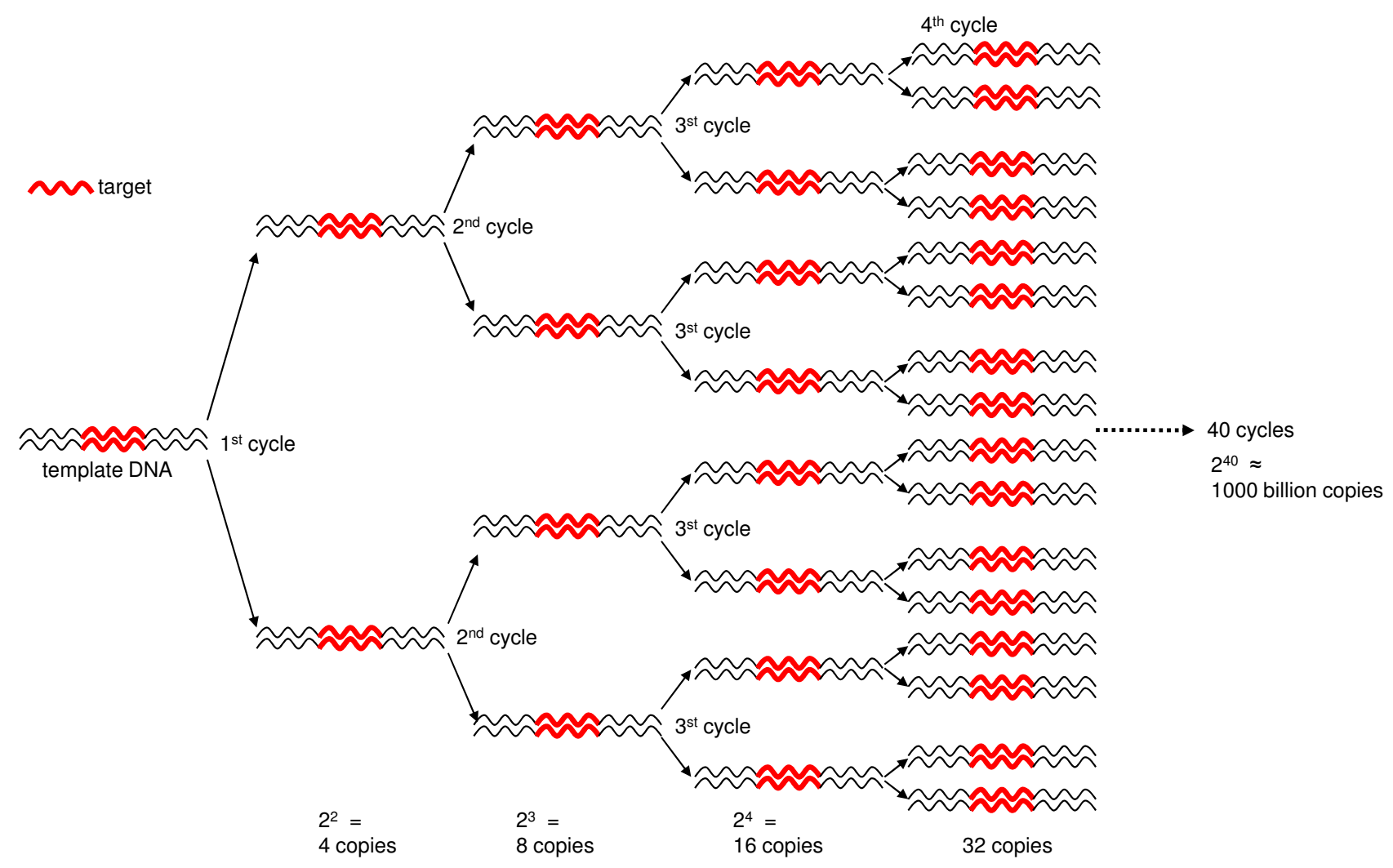

Figure 1. The exponential amplification of DNA in PCR.

obtained after the first cycle and second products obtained after the second cycle with undefined length and $x$ is the number of copies of the original template.
Potentially, after 30 PCR cycles there will be around $2^{30}$-fold amplification, assuming $100 \%$ efficiency during each cycle. The efficiency of a PCR will vary from template

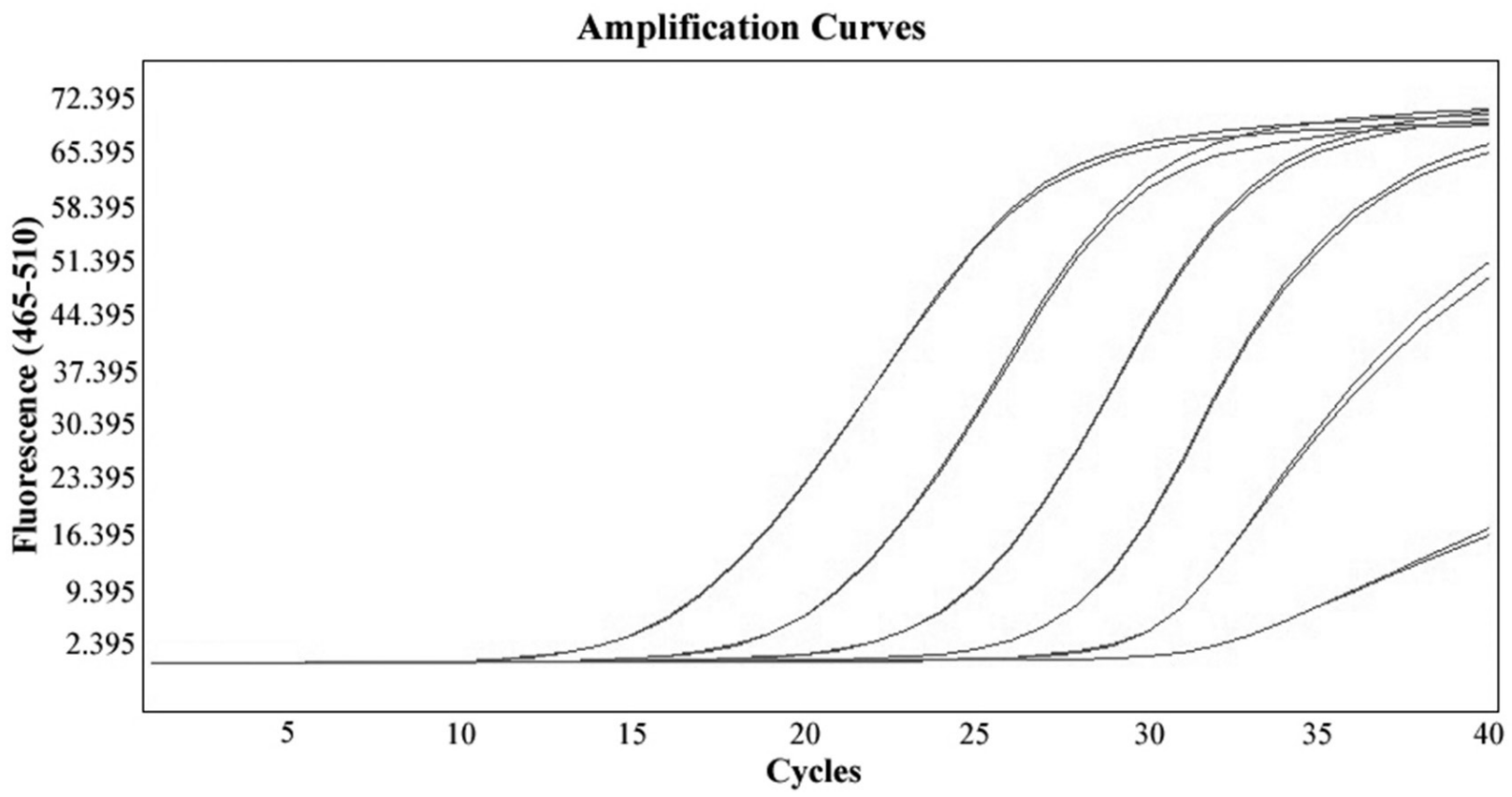

Figure 2. Amplification curves in semilogarithmic view obtained from serial dilutions of a target DNA. 


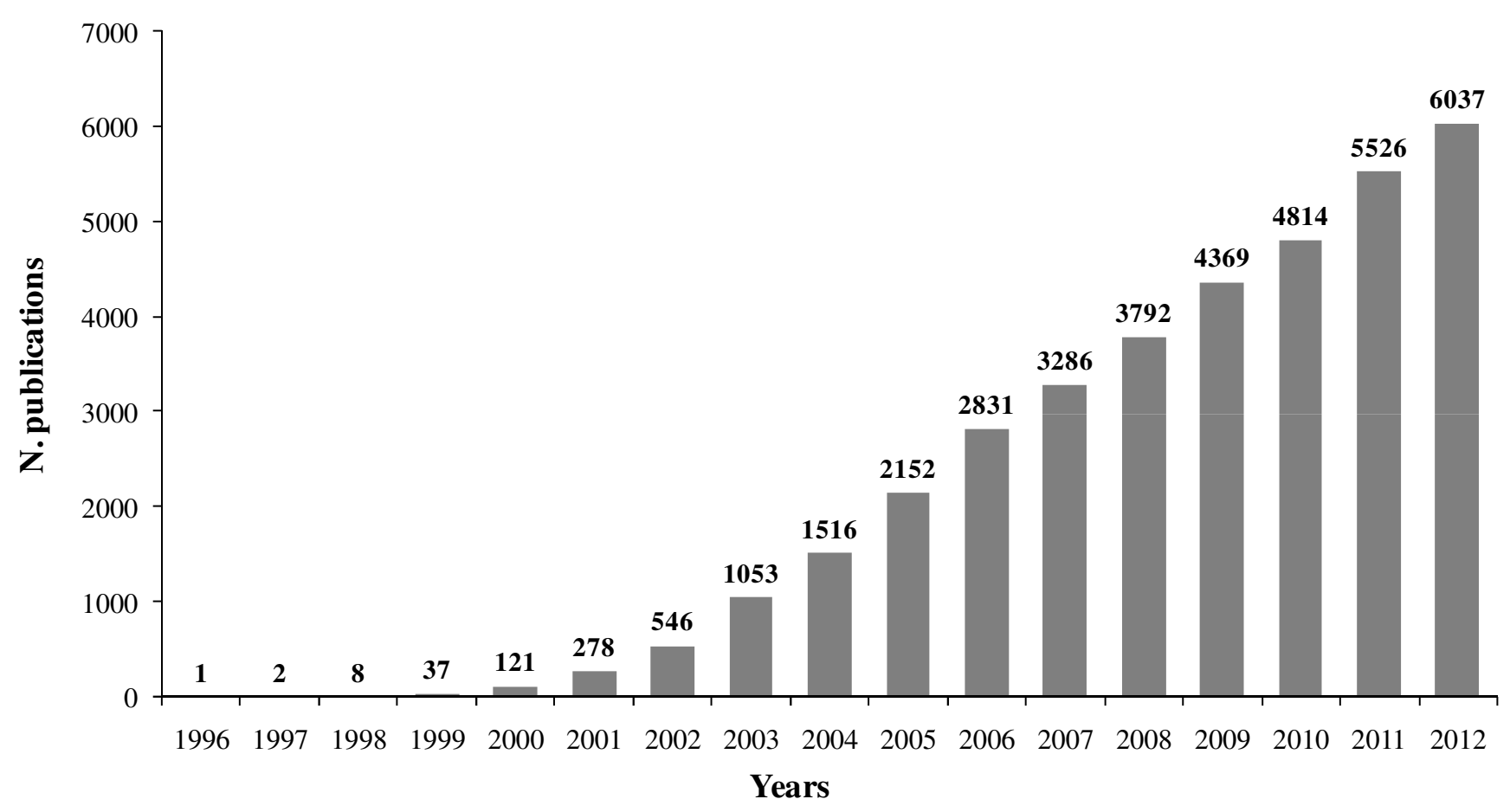

Figure 3. Result of a PubMed search using 'real-time PCR', sorted by year of publication.

to template and according to the degree of optimization that has been carried out.

\section{Multiplex PCR}

Whereas standard PCR usually uses one pair of primers to amplify a specific sequence, multiplex PCR allows the simultaneous amplification of more than one target sequence in a single reaction by using a set of primers (Elnifro et al., 2000; Higuchi et al., 1992; Wittwer et al., 2001). This saves considerable time and effort, and decreases the number of reactions that need to be performed to detect the desired targets in the sample. The presence of many PCR primers in a single tube can cause some problems, such as the increased formation of misprimed PCR products, 'primer dimers', and the amplification discrimination of longer DNA fragments (Atlas and Bej, 1994; Higuchi et al., 1992). For multiplex PCR, primers should be chosen with similar annealing temperatures. The lengths of amplified products should be similar; as large differences in the lengths of the target DNAs may favour the amplification of shorter targets over the longer ones, which results in differential yields of amplified products.

\section{Real-time PCR}

The development of real-time (q-) PCR represents a significant advance in many molecular techniques involving nucleic acids analysis. qPCR allows monitoring of the synthesis of new amplicon molecules during the PCR (i.e., in real time). Data is therefore collected throughout the PCR process, i.e. monitoring of the process of amplification in real time by using fluorescence, and not only at the end of the reaction (as occurs in conventional PCR) (Heid et al., 1996; Higuchi et al., 1993; Nazarenko et al., 1997). The qPCR results consist of amplification curves (Figure 2), that can be used to quantify the initial amounts of template DNA molecules with high precision over a wide range of concentrations (Schmittgen et al., 2000). Major advantages of qPCR are the closed-tube format (that avoids risks of carry-over contamination), fast and easy to perform analysis, the extremely wide dynamic range of quantification (more than eight orders of magnitude) (Heid et al., 1996) and the significantly higher reliability and sensitivity of the results compared to conventional PCR. qPCR can be used for many different purposes like conventional PCR, particularly for quantifying nucleic acids and for genotyping. Since the fist scientific work published in 1996 (Heid et al., 1996), the number of publications where qPCR is used has increased nearly exponentially (Figure 3 ).

\section{Chemistries or detection formats}

The fluorescence that is monitored along all the qPCR process can be detected by a unspecific detection strategy independent of the target sequence, e.g. through fluorescent dyes that have special fluorescent properties when bound to dsDNA, or by sequence-specific fluorescent oligonucleotide probes, i.e. a sequence-specific strategy.

\section{Unspecific detection formats}

Ethidium bromide was the first dye used for this purpose (Higuchi et al., 1993; Le Pecq and Paoletti, 1966; Wittwer et al., 1997). Other intercalating dyes such as YO-PRO-1, BEBO or SYBR Green I have since been used (Bengtsson et al., 2003; Ishiguro et al., 1995; Tseng et al., 1997). SYBR Green I is the most frequently used dsDNA-specific dye in qPCR. It is an asymmetrical cyanine dye, structurally related to the dsDNA-specific dyes YOYO-1 and TOTO-1 (Jin et al., 1994; Singer et al., 1994). Its binding affinity is more than 100 times higher than that of ethidium bromide. SYBR Green 


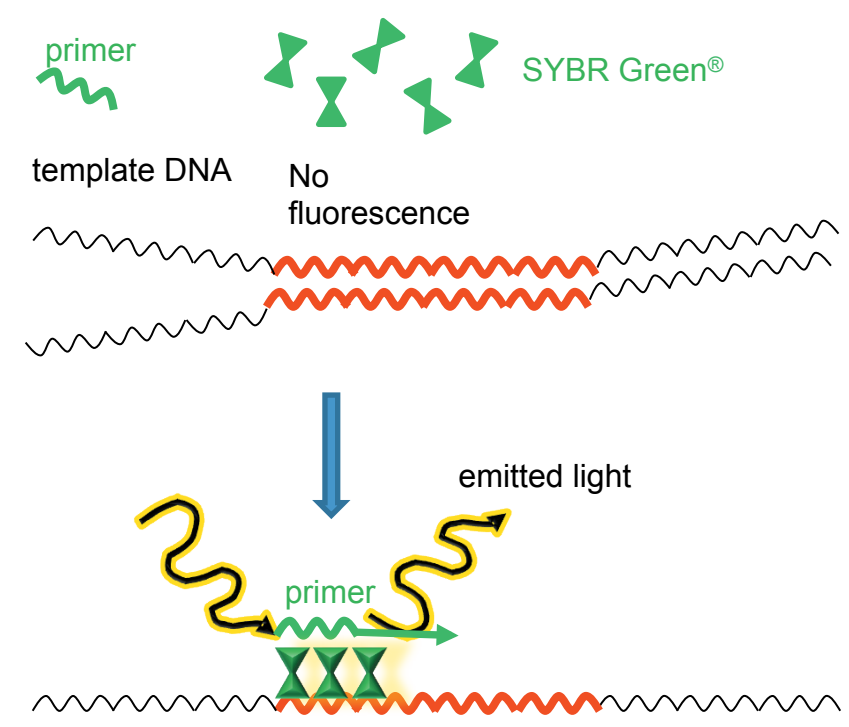

Fluorescence

Figure 4. Principle of detection using Sybr Green.

I largely binds sequence independently to the minor groove of ds-DNA. It can be excited with blue light with a wavelength of $480 \mathrm{~nm}$, and its emission spectrum is comparable to that of fluorescein with a maximum at $520 \mathrm{~nm}$ and a quantum yield of 0.8 (Jin et al., 1994). The fluorescence of the bound dye is above 1000 -fold higher than that of the free dye and, therefore, is well suited for monitoring the product accumulation during PCR (Wittwer et al., 1997; Morrison et al., 1998). When monitored in real time, this results in an increase in the fluorescence signal that can be observed during the polymerization step, and that falls off when the DNA is denatured (Figure 4). Consequently, fluorescence measurements have to be performed at the end of the elongation step of every PCR cycle. This method obviates the need for target-specific fluorescent probes, and hence it can be used with any pair of primers for any target, making its use less expensive (Giulietti et al., 2001). However, its major disadvantage is that specificity is determined entirely by the primers and thus the risk of amplifying non-specific PCR products has to be considered during optimization (Simpson et al., 2000). However, PCR product verification can be achieved at the end-point by plotting fluorescence as a function of temperature to generate a melting curve of the amplicon (Ririe et al., 1997).

The Amplifluor system is an unspecific detection system developed by Intergen co. AmpliFluor technology uses a universal energy-transfer hairpin primer (UniPrimer) which emits a fluorescent signal when unfolded during its incorporation into an amplification product. The UniPrimer contains a 18-nucleotide sequence ( $Z$ sequence: 5 '-act gaa cct gac cgt aca- $3^{\prime}$ ) at its $3^{\prime}$ end, that is also present at the $5^{\prime}$ end of one of the target-specific primers so that it anneals to the PCR product and acts as universal PCR primer. In the first step, the forward primer is extended. This extended product serves as template for the reverse primer in the second step. In the end, the polymerase opens the hairpin structure and a double-stranded PCR product is formed in which reporter and quencher are separated (Nazarenko et al., 1997) (Figure 5).

Sequence-specific fluorescent oligonucleotide probes There are different types of specific-sequence fluorescent probes, and they can be classified into two major groups, hydrolysis probes and hybridization probes, both types being homologous to the internal region amplified by the two primers. The fluorescence signal intensity can be related to the amount of PCR product (i) by a product-dependent decrease of the quench of a reporter fluorophore or (ii) by an increase of the fluorescence resonance energy transfer (FRET) from a donor to an acceptor fluorophore. FRET, also called Förster transfer, is the radiationless transfer of excitation energy by dipole-dipole interaction between fluorophores with overlapping emission and excitation spectra. The FRET and the quench efficiency are strongly dependent on the distance between the fluorophores (Förster, 1948; Clegg, 1992). Therefore, the PCR-productdependent change in the distance between the fluorophores is used to generate the sequence-specific signals. Several different formats can be used. In principle, all of them could function by a decrease of quench or an increase of FRET; in practice, most formats are based on a decrease of quench. The most commonly used fluorescent reporter dyes are FAM, TET (tetrachloro-6-car-boxyfluorescein), JOE (2,7-dimethoxy-4,5-dichloro-6-carboxy-fluorescein)

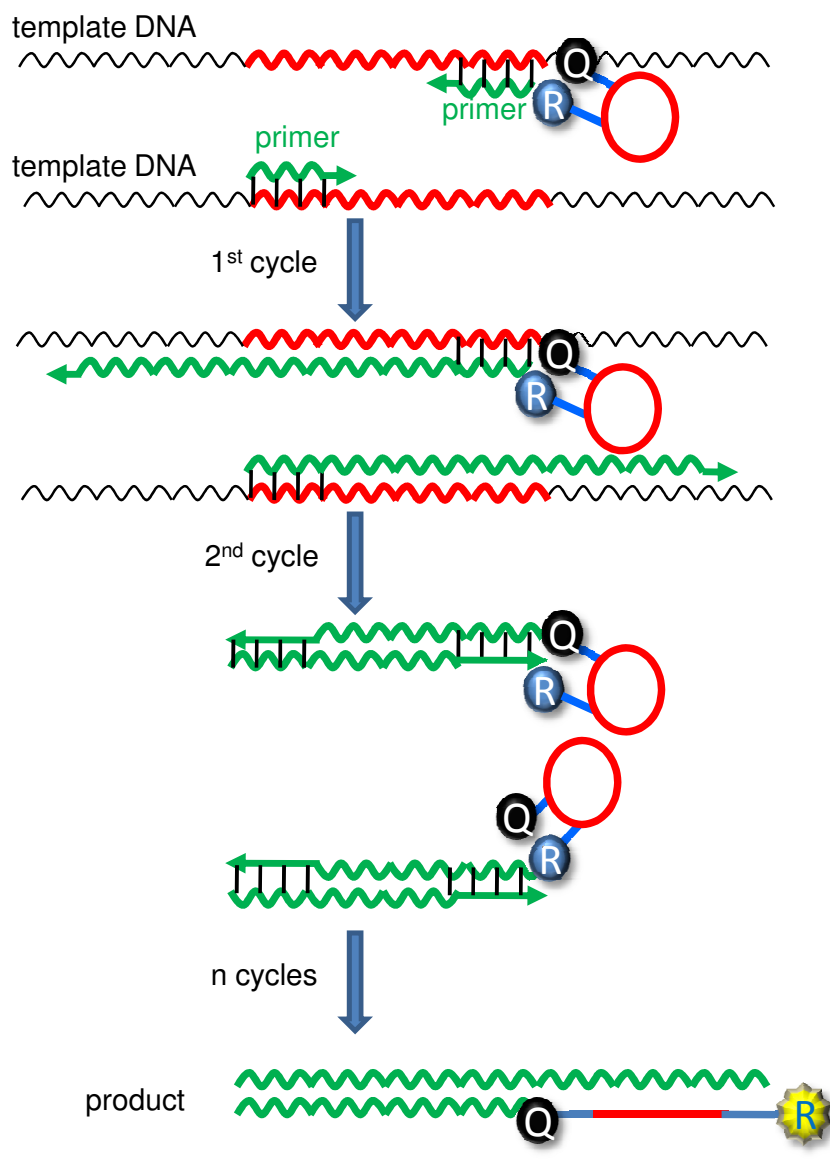

Figure 5. Principle of detection using AmpliFluor system. Adapted from Whitcombe et al. (1999). 
Table 1. Excitation and emission spectre of different fluorophores

\begin{tabular}{lll}
\hline Fluorophores & Excitation $(\mathrm{nm})$ & Emission $(\mathrm{nm})$ \\
\hline DABCYL & 453 & - \\
6-FAM & 492 & 515 \\
SYBR Green I & 497 & 520 \\
TET & 521 & 536 \\
JOE & 527 & 548 \\
HEX & 535 & 556 \\
TAMRA & 555 & 580 \\
ROX & 575 & 602 \\
VIC & 538 & 554 \\
\hline
\end{tabular}

or HEX (hexacholoro-6-carboxyfluorescein), and the most frequently used quenchers are TAMRA, DABCYL and Black Hole Quencher (BHQ) (Table 1). Many commercial fluorophores have been developed by biotech companies such as VIC, Alexa Fluor, or Yakina Yelow.

Sequence-specific probes allow multiplexing (Bernard et al., 1998; Dupont et al., 2002; Wittwer et al., 2001) and easy identification of point mutations (Giesendorf et al., 1998; Lay and Wittwer, 1997; Lyon, 2001). A common drawback of probe systems that use the decrease-ofquench mechanism is unwanted generation of a signal due to probe destruction (e.g. by unintentional hydrolysis of the probes by the Taq DNA polymerase) or by formation of secondary structures of the probes that lead to a decrease in quench (Wilhem and Pingoud, 2003).

Hydrolysis probes

The hydrolysis probes are cleaved when hybridized by the 5'-3 exonuclease activity of particular DNA polymerases (Holland et al., 1991) during the elongation phase of primers, yielding a real time measurable fluorescence emission directly proportional to the concentration of the target sequence (Heid et al., 1996). It usually utilizes either Taq or Tth polymerase, but any enzyme with equivalent
5'-3' exonuclease activity properties (e.g. Tfl) can be used (Gut et al. 1999). The best known hydrolysis probes are TaqMan ${ }^{\circledR}$ probes and TaqMan ${ }^{\circledR}$ MGB (minor groove binder) probes, both developed by Applied Biosystems.

A TaqMan probe is an oligonucleotide double-labelled with a reporter fluorophore at the $5^{\prime}$ end (reporter dye) and with a quencher internally or at the $3^{\prime}$ end (quencher dye). In addition, the probes must be blocked at their 3 '- end to prevent the extension during the annealing step. The TaqMan assay (Figure 6) uses three oligonucleotides. Two conventional primers allow amplification of the product, to which the TaqMan probe will anneal. The quencher dye absorbs the fluorescence of the reporter dye due to its proximity, which permits FRET. When the correct amplicon is amplified, the probe can hybridize to the target after the denaturation step. It remains hybridized while the polymerase extends the primers until it reaches the probe. Then, it displaces its $5^{\prime}$ end to hold it in a forked structure. The enzyme continues to move from the now free end to the bifurcation of the duplex, where cleavage takes place (Lyamichev et al. 1993). The quencher is hence released from the fluorophore, which now fluoresces after excitation (Heid et al., 1996; Holland et al., 1991; Gibson et al., 1996). As the polymerase will cleave the probe only while it remains hybridized to its complementary strand, the temperature conditions of the polymerization phase of the PCR must be adjusted to ensure probe binding. Most probes have a $T_{\mathrm{m}}$ of around $70^{\circ} \mathrm{C}$; therefore, the TaqMan system uses a combined annealing and polymerization step at $60-63^{\circ} \mathrm{C}$. This ensures that the probe remains bound to its target during the primer extension step. It also ensures maximum 5'-3' exonuclease activity of the Taq and Tth DNA polymerases (Tombline et al. 1996).

The TaqMan MGB probes are similar to TaqMan probes. They contain a non-fluorescent guencher (NFQ) and an oligopeptide at the $3^{\prime}$ end. This oligopeptide is a DNA minor groove binder (MGB), with very high affinity for the minor groove of AT-rich double-stranded DNA (Afonina et al., 1997). Addition of the MGB ligand significantly enhances duplex stability. The shorter the probe, the greater the MGB contribution to the overall duplex stability: with 12- to 18-bp oligonucleotides, it raises the $T_{\mathrm{m}}$ from $44-56^{\circ} \mathrm{C}$ up to $66-$ $70^{\circ} \mathrm{C}$ (Kutyavin et al., 2000). This allows designing suitable

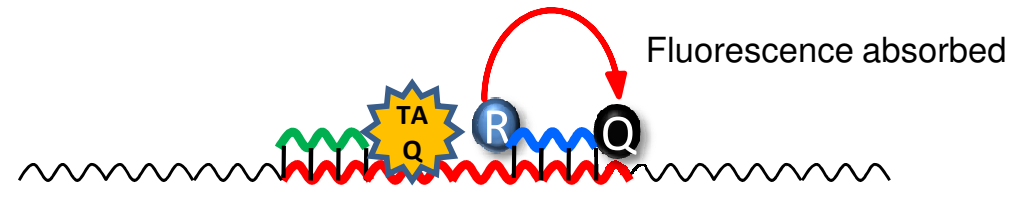

primer

probe

Reporter fluorescence

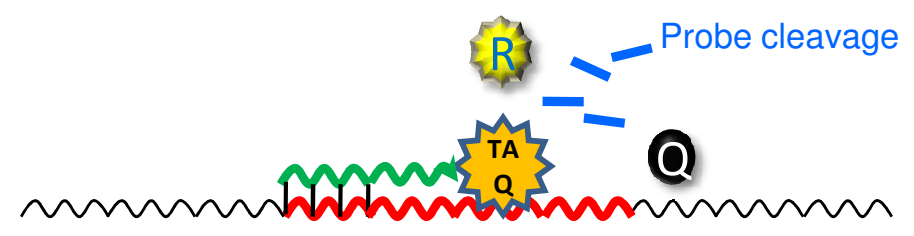

Figure 6. Principle of detection using TaqMan probes. 5'-3' polymerase and exonuclease activity of the Taq DNA polymerase (TAQ). $R$, reporter; $Q$, quencher. 


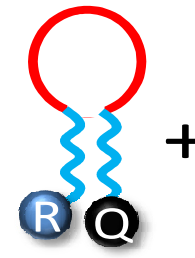

Molecular Beacon template DNA

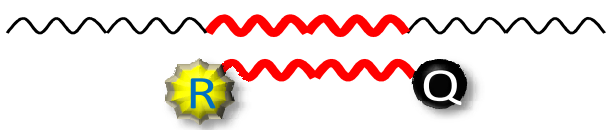

hybrid

Figure 7. Principle of detection using Molecular Beacons. During hybridization PCR step, the fluorophore and quencher components of molecular beacons become spatially separated and the fluorescence is generated. R: reporter; Q: quencher.

probes in sequences such as those rich in AT, in which conventional TaqMan probes require an excessive length.

\section{Hybridization probes}

In contrast to hydrolysis probes, hybridization probes are not hydrolysed during PCR. The fluorescence is generated by a change in its secondary structure during the hybridization phase, which results in an increase of the distance separating the reporter and the quencher dyes. The most relevant hybridization probes are those containing hairpins (Molecular Beacons, Scorpion primers, etc.), and FRET hybridization probes.

Molecular beacons form a stem-and-loop structure through complementary sequences on the $5^{\prime}$ and $3^{\prime}$ ends of the probe (Tyagi and Kramer 1996). The loop portion is complementary to the target nucleic acid (Tan et al., 2000). A reporter and a quencher fluorophore are attached one at the end of each arm. The quencher is a non-fluorescent chromophore that dissipates the energy it receives from the fluorophore as heat. The fluorescence is quenched when the probe is in a hairpin-like structure (stem-and-loop structure) due to the proximity between quencher and fluorophore allowing FRET (Cardullo et al., 1998; Stryer, 1978). In the presence of a complementary sequence, designed internal to the primer binding sites, the probe undergoes a conformational transition that forces the stem apart and results in the formation of a probe/target hybrid that is more stable than the former stem (Bonnet et al., 1999). This conformational change separates the fluorophore from the quencher and consequently FRET no longer occurs, thus increasing reporter fluorescence emission (Kostrikis et al., 1998; Tyagi et al., 1998) (Figure 7). Molecular beacons have been reported to be significantly more specific than conventional oligonucleotide probes of equivalent length, due to the presence of a stem structure (Bonnet et al., 1999; Kaboev et al., 2000; Tyagi et al., 1998). The main drawback of molecular beacons is associated with its design as the fluorescence yield is very sensitive to the hybridization conditions.

FRET probes or hybridization probes use four oligonucleotides, i.e. two primers and two sequencespecific probes (Wittwer et al., 1997). Each probe has a single label: either a donor fluorophore at the 3 '-end or an acceptor fluorophore at the 5 '-end. The emission spectrum of the donor fluorophore overlaps the excitation spectrum of the acceptor fluorophore. The FRET probes must be blocked at their 3 '-end to prevent the extension during the annealing step. The two probes hybridize to the target sequences in a head-to-tail arrangement, thus bringing the two dyes close (typically 1-5 nucleotides distant), allowing FRET. During PCR, only the donor fluorophore is excited. In solution, only background fluorescence is emitted by
A

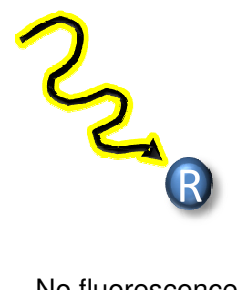

No fluorescence

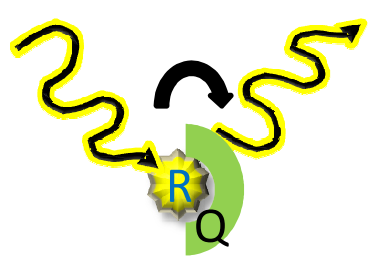

Fluorescence

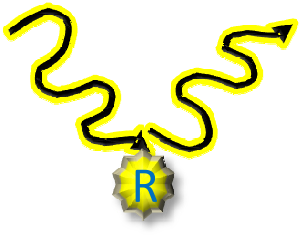

Fluorescence

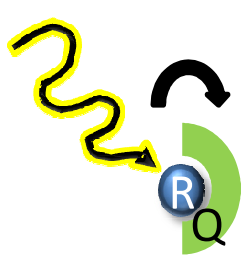

No fluorescence

\section{FRET}

Figure 8. Differences between detection using FRET probes and TaqMan probes. A. Energy transfer in FRET probes (the $e^{-}$ acceptor emits fluorescence when placed close to the $\mathrm{e}^{-}$donor. B. Energy transfer in hydrolysis probes (TaqMan) (the $\mathrm{e}^{-}$donor emits fluorescence when the distance to the acceptor or quencher is higher than $10 \mathrm{~nm}$. R: reporter. 


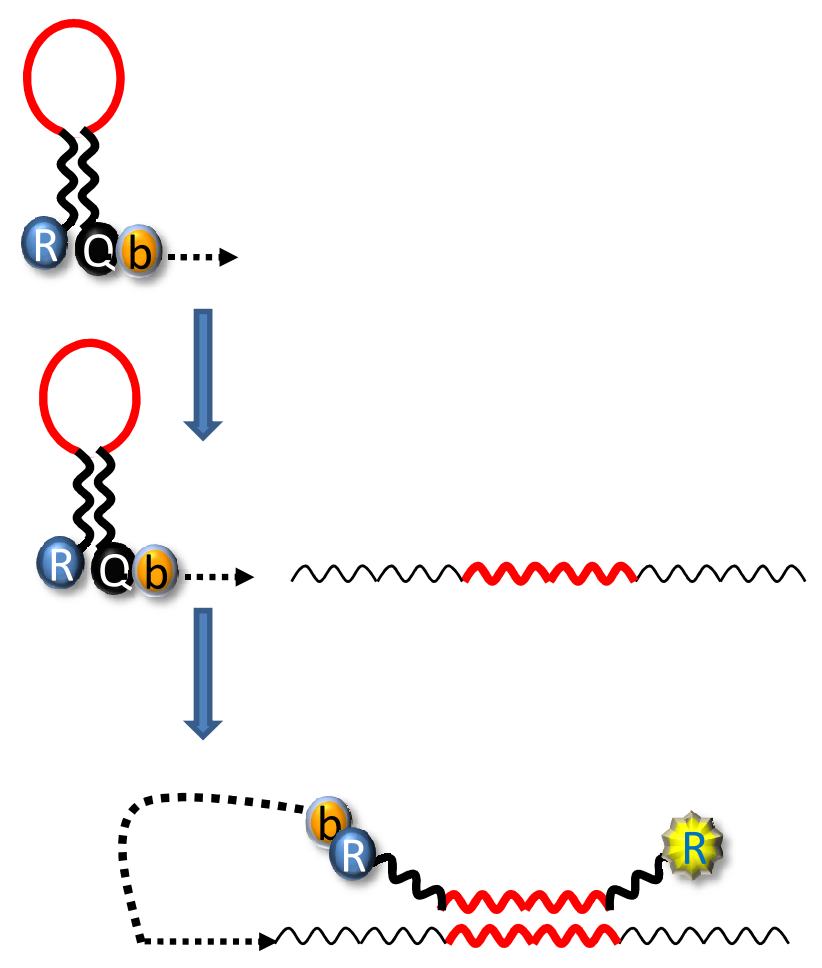

Figure 9. Principle of detection using Scorpion primers. R: reporter; Q: quencher; b: blocker. Adapted from Whitcombe et al. (1999).

the donor. During annealing, the two probes hybridize adjacently to their target sequence and thus the excitation energy is transferred by FRET from the donor dye in one of the probes to the acceptor dye in the other probe (Figure 8), allowing the acceptor dye to dissipate fluorescence at a different wavelength (Bernard and Wittwer, 2000). The use of two independent probes results in high specificity and flexibility for probe design. Furthermore, as the probes are not hydrolysed, fluorescence is reversible and allows the generation of melting curves.

Scorpion primers are structurally and functionally related to molecular beacons, but serve as primers in the PCR. They consist of a probe sequence linked to the $5^{\prime}$ end of a primer via a non-amplifiable stopper moiety (Whitcombe et al., 1999). The probe presents a fluorophore linked at the 5 '-end and a quencher at the $3^{\prime}$-end, and is held in a hairpin loop structure by complementary sequences on its 5 '- and 3 '-ends. This configuration brings the fluorophore in close proximity with the quencher and avoids fluorescence similarly to Molecular Beacons. In addition, the probe sequence is complementary to an internal region of the sequence extended by the adjacent primer. In the first step, the primer is extended, yielding a single-stranded template for the reverse primer in the second step. Upon hybridization, the hairpin is opened, producing a physical separation of the fluorophore and quencher such that increases in signal are observed (Figure 9). In contrast to the sunrise primers, the reverse extension is blocked by a hexethylene glycol group. This ensures that the reporter of the scorpion primer remains quenched in unspecific products like primer dimers (Whitcombe et al., 1998, 1999).

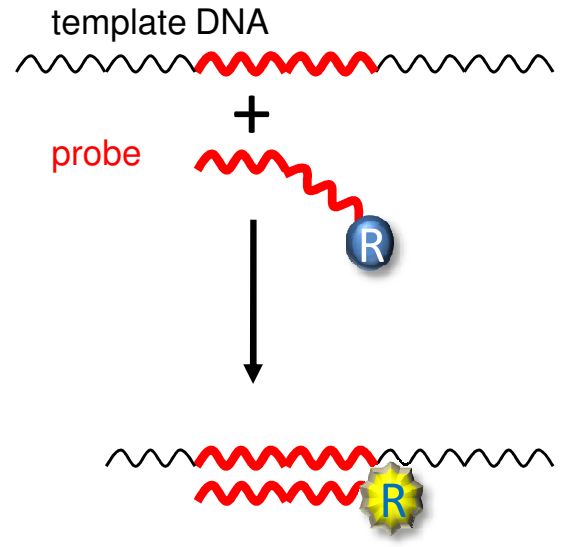

Figure 10. Principle of detection using light-up probes. R: reporter.

The light-up technology utilizes a nucleic acid analogue instead of natural DNA as sequence recognizing element (Isacsson et al., 2000). Light-up probes are peptide nucleic acids (PNAs) (Nielsen et al., 1991) that use thiazole orange, a derivative of cyanine, as reporter fluorophore (Svanvik et al., 2000a). It forms sequence-specific complexes with DNA and RNA which are more stable than double-stranded natural nucleic acids (lyer et al., 1995; Egholm et al., 1993). These features are attributed mainly to the chargeneutral nature of PNA, which eliminates the electrostatic repulsion between the hybridizing strands. The probe has low fluorescence when free in solution, however they show increased fluorescence intensity upon hybridization with DNA (Figure 10).

\section{Real-time PCR design}

There are already defined prerequisites to design TaqMan oligonucleotides, and most of them can be also applied to other probes. They are summarized in Table 2.

When a qPCR assay is designed, the most important parameters are the amplicon length and the $T_{\mathrm{m}}$ of the primers and probe. The optimal amplicon length should be less than $150 \mathrm{bp}$, but it is advisable to reduce the length below $80 \mathrm{bp}$. However, amplicons up to $300 \mathrm{bp}$ amplify efficiently. Shorter amplicons amplify more efficiently than longer ones and are more tolerant to suboptimal reaction conditions. This is because they are more likely to be denatured during the 92$95^{\circ} \mathrm{C} \mathrm{PCR}$ step, allowing the probes and primers to compete more effectively for binding to their complementary targets. As the extension rate of Taq polymerase is between 30 and 70 bases per second (Jeffreys et al., 1988), polymerization times as short as $5 \mathrm{~s}$ are sufficient to replicate such amplicon, making amplification of artefacts less likely and reducing the time of the assay. Primers are generally used in the $50-300 \mathrm{nM}$ range. Higher concentrations may promote mispriming and accumulation of non-specific products, and lower concentrations may lead to primer exhaustion, although target copy numbers will have been calculated well before. Non-specific priming can be minimized by selecting primers that have only one or two G/Cs within the $3^{\prime}$ last five nucleotides. A relative instability at the $3^{\prime}$ ends 
32 David Rodríguez-Lázaro and Marta Hernández

Table 2. Requisites for the design of oligonucleotides for RTi-PCR assays

\begin{tabular}{|c|c|c|}
\hline Parameter & Primers & Probes \\
\hline GC content (\%) & $30-80 \%$ & $30-80 \%$ \\
\hline \multirow[t]{2}{*}{ Calculated $T_{\mathrm{m}}$} & $\begin{array}{l}50-60^{\circ} \mathrm{C} \text {, always }>55^{\circ} \mathrm{C} \text { as UNG } \\
\text { works at } 50^{\circ} \mathrm{C}\end{array}$ & $68-70^{\circ} \mathrm{C}\left(5-10^{\circ} \mathrm{C}\right.$ above primer $\left.T_{\mathrm{m}}\right)$ \\
\hline & $\begin{array}{l}T_{m} \text { of the primers should not differ } \\
>2^{\circ} \mathrm{C}\end{array}$ & \\
\hline Runs of identical nucleotides & Maximum 3 (no Gs!!) & Maximum 3 (no Gs!!) \\
\hline Sequence length & Minimum 15 bp (15-30bp) & Maximum. $30 \mathrm{bp}$ \\
\hline Amplicon length & $\begin{array}{l}\text { The shorter the better. With TaqMan } \\
\text { probes, } 50-150 \text { bp }\end{array}$ & \\
\hline Distance forward primer to probe & Maximum 50 bp & \\
\hline Primer dimers, hairpin loops & Avoid & Avoid \\
\hline $3^{\prime}-$ instability $\left(3^{\prime}-\right.$ rule $)$ & $\begin{array}{l}\text { Primers only. Maximum two Gs/Cs } \\
\text { in the last } 5 \mathrm{bp}\end{array}$ & \\
\hline Autoquenching & & No $G$ at $5^{\prime}$-end \\
\hline $\mathrm{G}-\mathrm{C}$ ratio & & Select the strand with $\mathrm{C}>\mathrm{G}$ \\
\hline
\end{tabular}

makes primers less likely to hybridize transiently causing non-specific extension.

The $T_{\mathrm{a}}$ of the probe is also a critical parameter. Since amplification primers are extended as soon as they bind to their targets, the hybridization target sequence is rapidly masked with newly synthesized DNA. Therefore, the $T_{\mathrm{a}}$ of the probes must be significantly greater (approximately $10^{\circ} \mathrm{C}$ ) than that of the primers. The presence of $G$ at the $5^{\prime}$ end of the probe is to be avoided, because it slightly quenches the reporter signal, even after probe cleavage. Furthermore, the probe should contain more Cs than Gs; if this is not the case, the antisense probe should be used. The probe should never overlap with, or be complementary to either of the primers. The optimum concentration of fluorogenic probes will vary with the type of probe, as it depends on background fluorescence: quenching of hydrolysis probes is often below $100 \%$, and thus they produce background fluorescence levels higher than molecular beacons and FRET probes.

An additional requirement of the FRET system is that the target sequence should be located towards the $3^{\prime}$ end of the amplicon, close to the reverse primer-binding site on

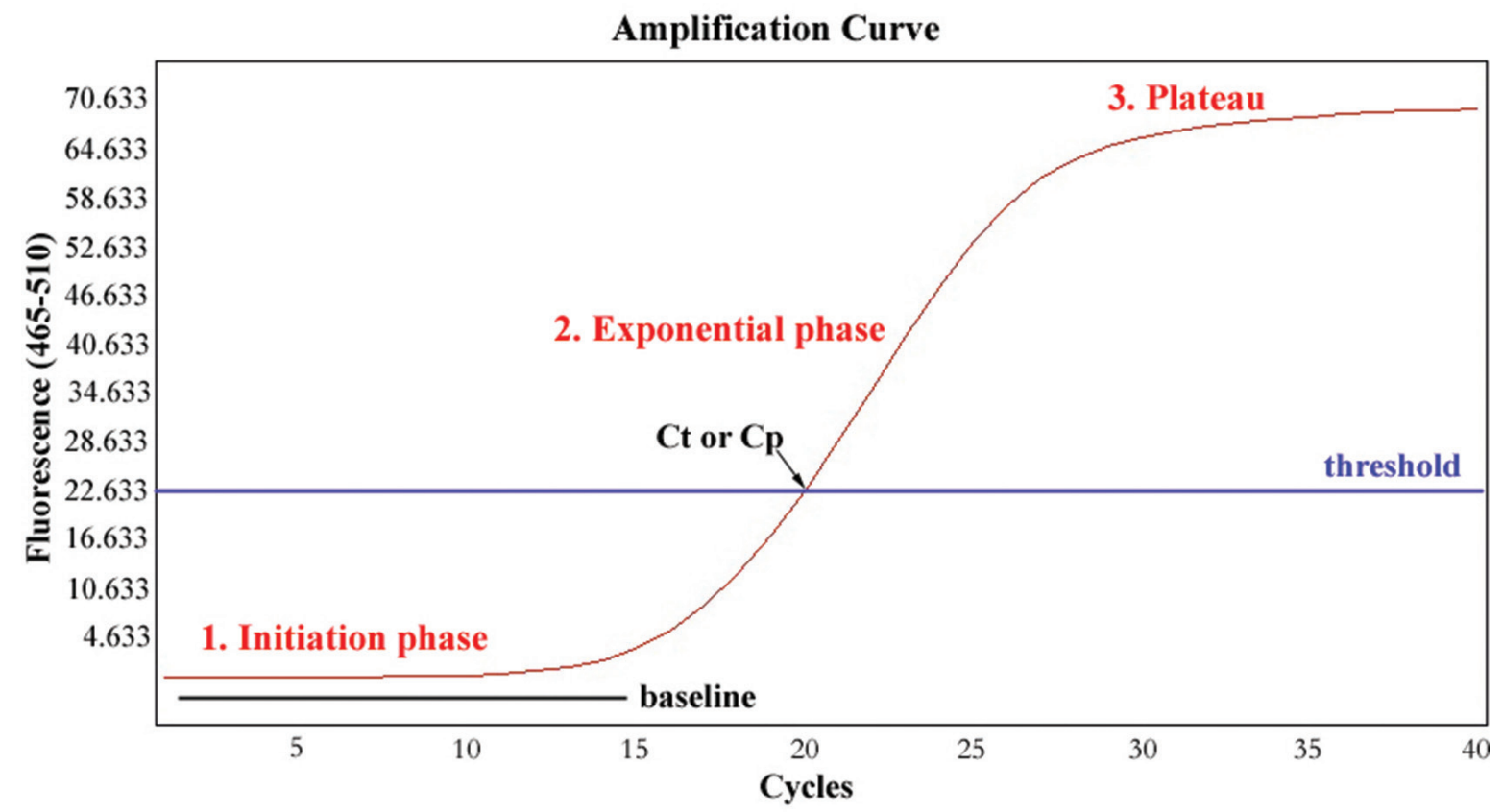

Figure 11. Phases of a PCR amplification curve. Red: amplification curve of a positive sample. Blue: threshold. Black: baseline cycles. 
Standard Curve

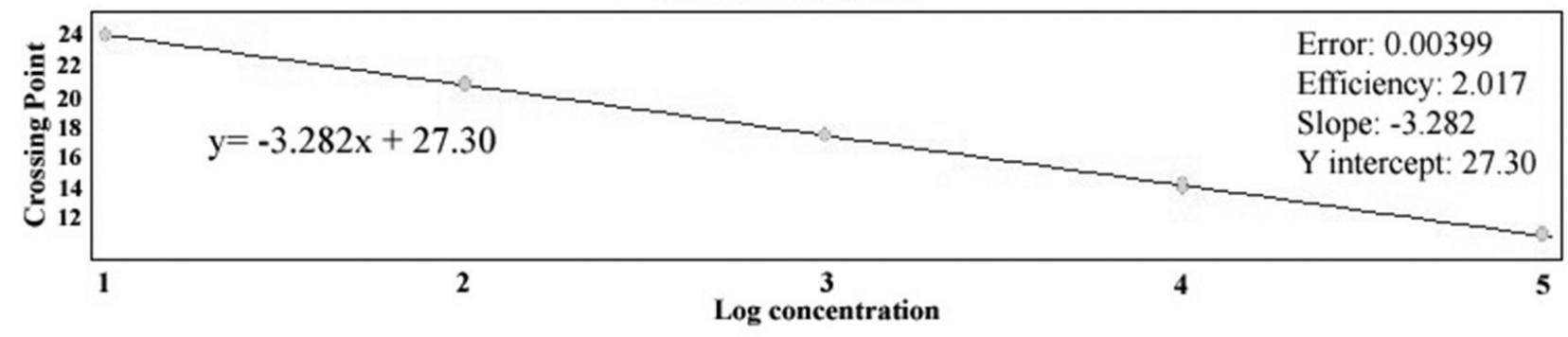

Figure 12. Standard curve built with DNA standards of known concentration (Figure 2). $x$-axis, initial amount of DNA (number of copies, ng, etc.); $y$-axis, $\mathrm{C}_{\mathrm{T}}$ values.

the opposite strand. As fluorescence is measured during the annealing phase, this arrangement allows the qPCR device to measure fluorescence before the polymerase displaces the probes. Paired probes used for quantification should have equal $T_{\mathrm{a}}$, whereas for mutational analysis the $T_{\mathrm{m}}$ of the sensor probe should be lower than that of the anchor probe, thus ensuring that the sensor probe controls the generation of the fluorescent signal.

\section{Quantification analysis}

As indicated above, the fluorescence emission during qPCR is proportional to the synthesized DNA, and can be can be visualized as an amplification plot (Figure 2). Typically, an amplification curve presents three different phases (Figure 11). The first is called the initiation phase, it occurs during the first PCR cycles where the emitted fluorescence can not be distinguished from the baseline. During the exponential or log phase there is an exponential increase in fluorescence, before the plateau phase is reached. In this last phase, the reagents are exhausted, and no increase in fluorescence is observed. Only in the exponential phase, quantification is possible.

A fluorophore (so-called passive reference) may be present in the PCR buffer in order to well-to-well normalize the fluorescence (Table 1). This helps to overcome the effects of pipetting errors. This normalization is accomplished by dividing the emission intensity of the reporter dye by the emission intensity of the passive reference to obtain a ratio, i.e. Rn (normalized reporter) for any given reaction. At any given cycle, $\mathrm{Rn}^{+}$is the $\mathrm{Rn}$ value of a reaction containing all components including the template and $\mathrm{Rn}^{-}$is the $\mathrm{Rn}$ value of an unreacted sample obtained from the early cycles of the PCR, i.e. those prior to a detectable increase in fluorescence, or from a reaction not containing template. The $\Delta \mathrm{Rn}$ is the difference between the $\mathrm{Rn}$ at the end point $\left(\mathrm{Rn}^{+}\right)$and at the starting point $\left(\mathrm{Rn}^{-}\right)$. It reliably indicates the magnitude of the signal generated by the given set of PCR conditions, and is proportional to the DNA amount during the exponential phase. The fluorescence emitted in the first cycles is used to calculate the baseline. A threshold is established at the fluorescence value of the average standard deviation of $\mathrm{Rn}$ for the baseline cycles, multiplied by an adjustable factor (usually 10 times). Alternatively, it can be established by the operator in order to compare different $q P C R$ experiments. The $C_{P}$ (crossing point, PCR cycle) or $\mathrm{C}_{\mathrm{T}}$ (threshold cycle) value is the cycle at which fluorescence achieves a defined threshold. It corresponds to the cycle at which a statistically significant increase in fluorescence $(\Delta R n$ or non-normalized) is first detected. This concept is the basics for accurate and reproducible quantification using qPCR; the number of cycles needed for the amplification-associated fluorescence to reach a specific threshold level of detection (the $C_{T}$ or $C_{P}$ value) is inversely correlated to the amount of nucleic acid that was in the original sample (Walker, 2002). This value always is in the exponential phase of amplification, when amplification is most efficient, and therefore quantification is least affected by reaction-limiting conditions.

The quantity of DNA at the start of the PCR can then be determined by interpolation of the resulting $C_{T}$ or $C_{p}$ value in a linear standard curve of values obtained from serially diluted known-amount standards (Figure 12). This standard curve correlates the emitted fluorescence $\left(C_{T}\right.$ or $C_{P}$ value) with the initial concentration of the standards used and the final result is achieved by interpolation of the produced fluorescence $\left(C_{T}\right.$ or $C_{P}$ value) during the amplification of the sample in this standard curve. In practice, such curves are linear over more than five orders of magnitude.

\section{Diagnostic real-time PCR parameters}

An international standard guideline (ISO 16140:2003) was prepared by CEN/TC275 in collaboration with the Technical Committee ISO/TC34 to establish the general principle and technical procedure for the validation of alternative methods in the field of microbiological analysis of food, animal feeding stuffs, and environmental and veterinary samples. Many of the performance criteria are well recognized and accepted by numerous internationally recognized organizations for standardization (ISO, EMEA, Codex Alimentarius, etc.). There are a series of concepts that define an analytical method and that are applied to diagnostic qPCR. The main concepts are: linearity, accuracy, precision, sensitivity and specificity.

Linearity can be defined as the ability of the method, when used with a given matrix, to give results that are in proportion to the amount of analyte present in the sample; that is, an increase in analyte corresponds to a proportional increase in the result (Anonymous, 2003). In the same manner, linearity has been defined by Paoletti and Weighardt (2002) as the proportionality of the signal to the amount of reference material, demonstrated by the calculation of a regression line with an adequate statistical method. The European Commission, in the particular case of genetically modified organisms (GMO), has established that 
the linearity within the range of applicability of the method should be not less than 98\% (Paoletti and Weighardt, 2002).

The accuracy describes the veracity of the test results (Skog and Leary, 1992), and can be defined as closeness of agreement between a test result and the accepted reference value (Anonymous, 1993; Paoletti and Weighardt, 2002; Hoorfar and Cook, 2003). The precision describes the reproducibility of the test results (Skog and Leary, 1992), and can be defined as the closeness of agreement between independent test results obtained under stipulated conditions of repeatability and reproducibility (Anonymous, 1993; Thompson et al., 2002).

Sensitivity is the ability of the alternative method to distinguish two different amounts of analyte (as measured by the reference method) within a given matrix, at a specified average value, or over the whole measurement range; that is, the minimal quantity variation which gives a significant variation of the measurement signal (Anonymous, 2003). The sensitivity differs from detection limit because it is calculated for each value of the measurement range. From a qualitative approach (i.e. for qualitative methods), the sensitivity can also be defined as the ability of the alternative method to detect the analyte when it is detected by the reference method (Anonymous, 2003; Hoorfar and Cook, 2003). The limit of detection is the smallest critical level detected with a probability $(1-\beta)$, which has to be well over $50 \%$, for example $95 \%$ (Anonymous, 2003) or 99\% (Hoorfar and Cook, 2003; Knutsson et al., 2002). The limit of detection has been also described as the smallest amount or concentration of analyte in the test that can be distinguished from zero (Anonymous, 1997; IUPAC, 1995; Thompson et al., 2002); the smallest number of culturable target microorganisms necessary to create a positive test response (Hoorfar and Cook, 2003), or the minimum level at which the analyte can reliably be detected with a probability of $95 \%$ (Paoletti and Weighardt, 2002). The limit of quantification is the smallest amount of analyte which can be measured and quantified with defined precision and accuracy by the method under validation (Anonymous, 2003). The Association of Analytical Communities (AOAC) defines the quantification limit for quantitative methods as: $\mathrm{LOQ}=10 \mathrm{SD}_{0}$ (Coleman et al., 1997).

The specificity is the degree to which a method is affected by the other components present in a multicomponent sample (Anonymous, 2003; Malorny et al., $2003 b$ ). In other words, the ability of a method to measure a given analyte within the sample without interference from non-target components or background noise (Anonymous, 2003). For food microbiology diagnostics other three related concepts have been defined: selectivity, inclusivity and exclusivity. Selectivity is defined as a measure of the degree of non-interference in the presence of non-target analytes (Anonymous, 2003). A method is selective if it can be used to detect the analyte and that a guarantee can be provided that the detected signal can only be a product by the specific analyte. Inclusivity is defined as the ability of an alternative method to detect the target analyte from a wide range of strains, and exclusivity as the lack of interference from a relevant range of non-target strains of the alternative method.

\section{Quality control of the real-time PCR}

The $\mathrm{qPCR}$ is an instrumental technique, and thus can produce false negative and false positive results. Contamination remains an issue for diagnostic laboratories (Pellet et al., 1999; Scherczinger et al., 1999). The main causes of production of false positive results are the accidental contamination of the samples or the reagents with positive samples (cross-contamination) or with amplification products and plasmid clones (carry-over contamination). To minimize these risks, several practices should be applied (Dieffenbach et al., 1995; Hernández, 2003; Mifflin, 2003). For example, it is advisable to establish space and time separation of pre- and post-amplification activities (Heinrich, 1991; Yap et al., 1994), in particular to separate pre-PCR activities from recombinant DNA activities, as well as to define two different pre-PCR areas: for the preparation of the master mix and for the addition the nucleic acid template to the reaction mixture. Each working area must have its own separate set of equipment, including pipettes, reagents, pipette tips, racks, centrifuges, vortex, lab coats, etc., and lab coats and gloves should be worn at all times, and gloves should be changed frequently. In addition, all reagents should be prepared in large volumes and aliquoted into single-use volumes for storage and free from contaminating nucleic acids and/or nucleases. Other actions to prevent or reduce the risk of PCR contaminations are the use of UV light before carrying out the experiments in the sample preparation lab and in the cabinet where the amplification mixture is prepared, and samples should be manipulated with specialized barrier or positive-displacement pipettes, which prevent the carry-over of aerosols created during pipetting. Finally, the use of uracil-DNA-glycosylase (UDG; also called uracil- $\mathrm{N}$-glycosylase or UNG) is recommended, as it can eliminate the contamination arising from PCR products (Longo et al., 1990; Thornton et al., 1992). During amplification, dTTP is substituted with dUTP, so the DNA product will contain dU instead of dT. Subsequent PCR runs are programmed to include a $50^{\circ} \mathrm{C}$ incubation step with UDG, which will mediate cleavage of any contaminating DNA strands containing dU.

In addition to the prevention measures for avoiding contamination, a suite of controls must be included in order to correctly interpret the results of a qPCR.

\section{Application of real-time PCR for the detection of food- borne pathogens}

Bacterial detection and control are two key aspects in food microbiology (Stewart, 1997). Microbiological quality control programmes are increasingly applied throughout food chain production in order to minimize the risk of infection for the consumer. Thus, the availability of reliable, rapid and accepted test systems to detect the presence or absence, or even the degree of contamination of pathogens, becomes increasingly important for the agricultural and food industry. Such systems would also find a place within the framework of legislative control measures. During the last 15 years, PCR has significantly contributed to this field (RodríguezLázaro, 2013).

Traditional and standardized analysis of food for the presence of microorganisms relies on the enrichment and isolation of presumptive colonies of bacteria on agar media, using approved diagnostic artificial media. This is generally followed by biochemical and/or serological identification. 
Traditional methods of detection, although reliable and efficient, require several days to weeks before results are produced. Furthermore, phenotypic properties by which the bacteria are identified may not be always expressed; and when expressed, they may be difficult to interpret and classify. Another disadvantage of traditional methods is that cells which are viable but otherwise non-culturable cannot be detected, e.g. some stressed Campylobacter spp. (Rollins and Colwell, 1986; Tholozan et al., 1999). Thus, introduction of amplification techniques in microbial diagnostics has been established in research laboratories as a valuable alternative to traditional detection methods. The most extensively used amplification method is PCR, but other methods have also been developed such as NASBA, the Q-beta replicase amplification system and the ligase chain reaction (LCR), although until now, they have had limited practical relevance for food monitoring and control. Speed, excellent detection limit, selectivity, specificity, sensitivity and potential for automation are among the most important advantages of qPCR. These advantages compared to traditional detection methods might well encourage end-users to adopt amplification techniques in routine testing for food-borne pathogens.

\section{References}

Afonina, I., Zivarts, M., Kutyavin, I., Lukhtanov, E., Gamper, H., and Meyer, R.B. (1997). Efficient priming of PCR with short oligonucleotides conjugated to a minor groove binder. Nucleic Acids Res. 25, 2657-2660.

Anonymous (1993). ISO 3534-1,1993 Statistics. Vocabulary and symbols. Part 1, Probability and general statistical terms. International Organization for Standardization, Geneva, Switzerland.

Anonymous (1997). ISO 11843-1,1997 Capacity of detection. International Organization for Standardization, Geneva, Switzerland.

Anonymous (2003). ISO 16140,2003, Microbiology of food and animal feeding stuffs - Protocol for the validation of alternative methods. International Organization for Standardization, Geneva, Switzerland.

Atlas, R.M., and Bej, A.K. (1994). Polymerase Chain Reaction. In, Gerhardt, P., Murrey, R.G.E., Wood, W.A., and Krieg, N.R. (eds.). Method for general and molecular bacteriology. (Washington. D.C., USA: American Society for Microbiology), pp. 418-435.

Bengtsson, M., Karlsson, H.J., Westman, G., and Kubista, M. (2003). A new minor groove binding asymmetric cyanine reporter dye for real-time PCR. Nucleic Acids Res. 31, e45.

Bernard, P.S., and Wittwer, C.T. (2000). Homogeneous amplification and variant detection by fluorescent hybridization probes. Clin. Chem. 46, 147-148.

Bernard, P.S., Ajioka, R.S., Kushner, J.P., and Wittwer, C.T. (1998). Homogeneous multiplex genotyping of hemochromatosis mutations with fluorescent hybridization probes. Am. J. Pathol. 153, 1055-1061.

Bonnet, G., Tyagi, S., Libchaber, A., and Kramer, F.R. (1999). Thermodynamic basis of the enhanced specificity of structured DNA probes. Proc. Natl. Acad. Sci. USA. 96, 6171-6176.

Cardullo, R.A., Agrawal, S., Flores, C., Zamecnik, P.C., and Wolf, D.E. (1988). Detection of nucleic acid hybridization by nonradiative fluorescence resonance energy transfer.
Proc. Natl. Acad. Sci. USA 85, 8790-8794.

Cha, R.S., and Tilly, W.G. (1993).. Specificity, efficiency and fidelity of PCR. PCR Methods Appl. 3, 518-529.

Chisholm. J., Conyers. C., Booth, C., Lawley, W., and Hird, $H$. (2005). The detection of horse and donkey using realtime PCR. Meat Sci. 70, 727-32.

Clegg, R.M. (1992). Fluorescence resonance energy transfer and nucleic acids. Methods Enzymol. 211, 353388.

Dieffenbach, C.W., Lowe, T.M.J., and Dveksler, G.S. (1995). General concepts for PCR primers design. In, Dieffenbach, C.W., and Dveksler, G.S. (eds.) PCR primers, a laboratory manual. (Cold Springer Harbour, USA: Cold Springer Harbour Laboratory Press), pp. 133142.

Dupont, M., Goldsborough, A., Levayer, T., Savare, J., Rey, J.M., Rossi, J.F., Demaille, J., and Lavabre-Bertrand, T. (2002). Multiplex fluorescent RT-PCR to quantify leukemic fusion transcripts. Biotechniques 33, 158-164.

Egholm, M., Buchardt, O., Christensen, L., Behrens, K., Freier, S.M., Driver, D.A., Berg, R.H., Kim, S.K., Nordén, B., and Nielsen, P.E. (1993). PNA hybridizes to complementary oligonucleotides obeying the WatsonCrick hydrogen-bonding rules. Nature 365, 566-568.

Elnifro, E.M., Ashshi, A.M., Cooper, R.J., and Klapper, P.E. (2000). Multiplex PCR, optimization and application in diagnostic virology. Clin. Microbiol. Rev. 13, 559-570.

Förster, T. (1948). Zwischen molekulare energiewanderung und fluoreszenz. Ann. Phys. 6, 55-75.

Gibson, U.E., Heid, C.A., and Williams, P.M. (1996). A novel method for real time quantitative RT-PCR. Genome Res. 6, 995-1001.

Giesendorf, B.A., Vet, J.A., Tyagi, S., Mensink, E.J., Trijbels, F.J., and Blom, H.J. (1998). Molecular beacons, a new approach for semi-automated mutation analysis. Clin Chem. 44, 482-486.

Giulietti, A., Overbergh, L., Valckx, D., Decallonne, B., Bouillon, R., and Mathieu, C. (2001). An overview of realtime quantitative PCR, applications to quantify cytokine gene expression. Methods. 25, 386-401.

Gut, M., Leutenegger, C.M., Huder, J.B., Pedersen, N.C., and Lutz, H. (1999). One-tube fluorogenic reverse transcription-polymerase chain reaction for the quantitation of feline coronaviruses. J. Virol. Methods. 77, 37-46.

Heid, C.A., Stevens, J., Livak, K.J., and Williams, P.M. (1996). Real time quantitative PCR. Genome Res. 6, 986-994.

Heinrich, M. (1991). PCR carry-over. Biotech Forum Europe. Int. J. Biotechnol. Heft. 10, 594-597.

Hernández, M. (2003). Detección, identificación y cuantificación de organismos modificados genéticamente (OMG) en alimentos mediante PCR a tiempo real. Tesis Doctoral. Universidad de León, Spain.

Hernández, M., Rodriguez-Lazaro, D., and Ferrando, A. (2005). Current methodology for detection, identification and quantification of genetically modified organisms. Current Anal. Chem. 1, 203-221.

Higuchi, R., Dollinger, G., Walsh, P.S., and Griffith, R. (1992). Simultaneous amplification and detection of specific DNA sequences. Biotechnology (N.Y.) 10, 413-417.

Higuchi, R., Fockler, C., Dollinger, G., and Watson, R. (1993). Kinetic PCR analysis, real-time monitoring of 
DNA amplification reactions. Biotechnology (N.Y.) 11, 1026-1030.

Holland, P.M., Abramson, R.D., Watson, R., and Gelfand, D.H. (1991). Detection of specific polymerase chain reaction product by utilizing the $5^{\prime}-3^{\prime}$ exonuclease activity of Thermus aquaticus DNA polymerase. Proc. Natl. Acad. Sci. USA 88, 7276-7280.

Hübner, P., Burgener, M., and Lüthy, J. (1997).. Application of molecular biology for the identification of fish. In, Amadò, R., and Battaglia, R. (eds.) Authenticity and Adulteration of food, the analytical approach. Proceedings of European Food Chem. Congress IX, 24-26 September, Interlaken, Switzerland, pp. 49-54.

Innis, M.A., Gelfand, D.H., and Sninsky, J.J. (1999). PCR Applications, protocols for functional genomics. (San Diego, USA: Academic Press).

Isacsson, J., Cao, H., Ohlsson, L., Nordgren, S., Svanvik, N., Westman, G., Kubista, M., Sjoback, R., and Sehlstedt, U. (2000). Rapid and specific detection of PCR products using light-up probes. Mol. Cell. Probes 14, 321-328.

Ishiguro, T., Saitoh, J., Yawata, H., Yamagishi, H., Iwasaki, S., and Mitoma, Y. (1995). Homogeneous quantitative assay of hepatitis $C$ virus RNA by polymerase chain reaction in the presence of a fluorescent intercalater. Anal. Biochem. 229, 207-213.

IUPAC (1995). Nomenclature in evaluation of analytical methods, including quantification and detection capabilities. IUPAC Recommendation. Pure Appl. Chem. 67, 1699-1723.

Iyer, M., Norton, J.C., and Corey, D.R. (1995). Accelerated hybridization of oligonucleotides to duplex DNA. J. Biol. Chem. 270, 14712-14717.

Jeffreys, A.J., Wilson, V., Neumann, R., and Keyte, J. (1988). Amplification of human minisatellites by the polymerase chain reaction, towards DNA fingerprinting of single cells. Nucleic Acids Res. 16, 10953-10971.

Jin, X., Yue, S., Wells, K.S., and Singer, V.L. (1994). SYBR Greeen I: a new fluorescent dye optimized for detection of picogram amounts of DNA in gels. Biophys. J. 66, A159.

Kaboev, O.K., Luchkina, L.A., Tretiakov, A.N., and Bahrmand, A.R. (2000). PCR hot start using primers with the structure of molecular beacons (hairpin-like structure). Nucleic Acids Res. 28, E94.

Knutsson, R., Löfström, C., Grage, H., Hoorfar, J., and Rådström, P. (2002). Modeling of $5^{\prime}$ nuclease realtime responses for optimization of a high-throughput enrichment PCR procedure for Salmonella enterica. J. Clin. Microbiol. 40, 50-62.

Kostrikis, L.G., Tyagi, S., Mhlanga, M.M., Ho, D.D., and Kramer, F.R. (1998). Spectral genotyping of human alleles. Science 279, 1228-1229.

Kutyavin, I.V., Afonina, I.A., Mills, A., Gorn, V.V., Lukhtanov, E.A., Belousov, E.S., Singer, M.J., Walburger, D.K., Lokhov, S.G., Gall, A.A., et al. (2000). 3'-minor groove binder-DNA probes increase sequence specificity at PCR extension temperatures. Nucleic Acids Res. 28, 655-661.

Lay, M.J., and Wittwer, C.T. (1997). Real-time fluorescence genotyping of factor $\mathrm{V}$ Leiden during rapid-cycle PCR. Clin Chem. 43, 2262-2267.

Le Pecq, J.B., and Paoletti, C. (1966). A new fluorometric method for RNA and DNA determination. Anal. Biochem. 17, 100-107.

Longo, M.C., Berninger, M.S., and Hartley, J.L. (1990).
Use of uracil DNA glycosylase to control carry-over contamination in polymerase chain reactions. Gene 93,125-128.

Lyamichev, V., Brow, M.A., and Dahlberg, J.E. (1993). Structure-specific endonucleolytic cleavage of nucleic acids by eubacterial DNA polymerases. Science 260, 778-783.

Lyon, E. (2001). Mutation detection using fluorescent hybridization probes and melting curve analysis. Exp. Rev. Mol. Diagn. 1, 92-101.

Malorny, B., Tassios, P.T., Rådström, P., Cook, N., Wagner, M., and Hoorfar, J. (2003). Standardization of diagnostic PCR for the detection of food-borne pathogens. Int. J. Food Microbiol. 83, 39-48.

Miffin, T.E. (2003). Setting up a PCR laboratory. In, Dieffenbach, C.W., and Dveksler, G.S. (eds.) PCR Primers, A Laboratory Manual. (Cold Springer Harbour, USA: Cold Springer Harbour Laboratory Press), pp. 5-14.

Morrison, T.B., Weis, J.J., and Wittwer, C.T. (1998). Quantification of low-copy transcripts by continuous SYBR Green I monitoring during amplification. Biotechniques 24, 954-962.

Mullis, K., Faloona, F., Scharf, S., Saiki, R., Horn, G., and Erlich, H. (1986). Specific enzymatic amplification of DNA in vitro: the polymerase chain reaction. Cold Spring Harbor Symp. Quant. Biol. 51, 263-273.

Nazarenko, I., Bhatnagar, S.K., and Hohman, R.J. (1997). A closed tube format for amplification and detection of DNA based on energy transfer. Nucleic Acids Res. 25, 2516-2521.

Nielsen, P.E., Egholm, M., Berg, R.H., and Buchardt, O. (1991). Sequence-selective recognition of DNA by strand displacement with a thymine-substituted polyamide. Science 254, 1497-1500.

Paoletti, C., and Wighardt, F. (2002). Definition of prevalidation performance requirements. 4th meeting of the European Network of GMO Laboratories (ENGL), 29-30 April, 2002. (Ispra, Italy: EU Joint Research Centre).

Pellett, P.E., Spira, T.J., Bagasra, O., Boshoff, C., Corey, L., de Lellis, L., Huang, M.L., Lin, J.C., Matthews, S., Monini, P., et al. (1999). Multicenter comparison of PCR assays for detection of human herpesvirus 8 DNA in semen. J. Clin. Microbiol. 37, 1298-1301.

Ririe, K.M., Rasmussen, R.P., and Wittwer, C.T. (1997). Product differentiation by analysis of DNA melting curves during the polymerase chain reaction. Anal. Biochem. 245, 154-160.

Rodríguez-Lázaro, D., Lombard, B., Smith, H., Rzezutka, A., D'Agostino, M., Helmuth, R., Schroeter, A., Malorny, B., Miko, A., Guerra, B., et al. (2007). Trends in analytical methodology in food safety and quality: monitoring microorganisms and genetically modified organisms. trends food sci. Technol. 18, 306-319.

Rodríguez-Lázaro, D. (2013). Real-Time PCR in Food Science: Current Technology and Applications (Norfolk, UK: Caister Academic Press).

Rollins, D.M., and Colwell, R.R. (1986). Viable but nonculturable stage of Campylobacter jejuni and its role in survival in the natural aquatic environment. Appl. Environ. Microbiol. 52, 531- 538.

Saiki, R.K., Scharf, S., Faloona, F., Mullis, K.B., Horn, G.T., Erlich, H.A., and Arnheim, N. (1985). Enzymatic amplification of beta-globin genomic sequences and 
restriction site analysis for diagnosis of sickle cell anemia. Science 230, 1350-1354.

Saiki, R.K., Gelfand, D.H., Stoffel, S., Scharf, S.J., Higuchi, R., Horn, G.T., Mullis, K.B., and Erlich, H.A. (1988).. Primer-directed enzymatic amplification of DNA with a thermostable DNA polymerase. Science 239, 487-491.

Scherczinger, C.A., Ladd, C., Bourke, M.T., Adamowicz, M.S., Johannes, P.M., Scherczinger, R., Beesley, T., and Lee, H.C. (1999). A systematic analysis of PCR contamination. J. Forensic. Sci. 44, 1042-1045.

Schmittgen, T.D., Zakrajsek, B.A., Mills, A.G., Gorn, V., Singer, M.J., and Reed, M.W. (2000). Quantitative reverse transcription-polymerase chain reaction to study mRNA decay, comparison of endpoint and real-time methods. Anal. Biochem. 285, 194-204.

Simpson, D.A.C., Feeney, S., Boyle, C., and Stitt, A.W. (2000). Retinal VEGF mRNA measured by SYBR green I fluorescence, A versatile approach to quantitative PCR. Mol. Vis. 6, 178-183.

Singer, V.L., Jin, X., Ryan, D., and Yue, S. (1994). Biomed. Products 19, 72-86.

Skoog, D.A., and Leary, J.J. (1992). Principles of Instrumental Analysis. (London, UK, Saunders College Publishing).

Stewart, D., and Gendel, S.M. (1998). Specificity of the BAX polymerase chain reaction system for detection of the food-borne pathogen Listeria monocytogenes. J. AOAC Int. 81, 817-822.

Stryer, L. (1978). Fluorescence energy transfer as a spectroscopic ruler. Annu. Rev. Biochem. 47, 819-846.

Svanvik, N., Stahlberg, A., Sehlstedt, U., Sjoback, R., and Kubista, M. (2000). Detection of PCR products in real time using light-up probes. Anal. Biochem. 287,179-182.

Tan, W., Fang, X., Li, J., and Liu, X. (2000). Molecular beacons, a novel DNA probe for nucleic acid and protein studies. Chemistry 6, 1107-1111.

Tholozan, J.L., Cappelier, J.M., Tissier, J.P., Delattre, G., and Federighi, M. (1999). Physiological characterization of viable-but-nonculturable Campylobacter jejuni cells. Appl. Environ. Microbiol. 65, 1110-1116.

Thompson, M., Ellison, S.L.R., and Wood, R. (2002). Harmonized guidelines for single-laboratory validation of methods of analysis (IUAPC Technical Report). Pure Appl. Chem. 74, 835-855.
Thornton, C.G., Hartley, J.L., and Rashtchian, A. (1992). utilizing uracil DNA glycosylase to control carry-over contamination in PCR, characterization of residual UDG activity following thermal cycling. BioTechniques 13, 180183.

Tombline, G., Bellizzi, D., and Sgaramella, V. (1996). Heterogeneity of primer extension products in asymmetric PCR is due both to cleavage by a structure-specific exo/endonuclease activity of DNA polymerases and to premature stops. Proc. Natl. Acad. Sci. U.S.A. 93, 27242728.

Tseng, S.Y., Macool, D., Elliott, V., Tice, G., Jackson, R., Barbour, M., and Amorese, D. (1997). An homogeneous fluorescence polymerase chain reaction assay to identify Salmonella. Anal. Biochem. 245, 207-212.

Tyagi, S., and Kramer, F.R. (1996). Molecular Beacons, probes that fluoresce upon hybridization. Nat. Biotechnol. 14, 303-308.

Tyagi, S., Bratu, D.P., and Kramer, F.R. (1998). Multicolour molecular beacons for allele discrimination. Nature Biotechnol. 16, 49-53.

Walker, N. (2002). A technique whose time has come. Science 296, 557-559.

Whitcombe, D., Brownie, J., Gillard, H.L., McKechnie, D., Theaker, J., Newton, C.R., and Little, S. (1998). A homogeneous fluorescence assay for PCR amplicons, its application to real-time, single-tube genotyping. Clin. Chem. 44, 918-923.

Whitcombe, D., Theaker, J., Guy, S.P., Brown, T., and Little, S. (1999). Detection of PCR products using self-probing amplicons and fluorescence. Nat. Biotechnol. 17, 804807.

Wilhelm, J., and Pingoud, A. (2003). Real-time polymerase chain reaction. Chembiochemistry 4, 1120-1128.

Wittwer, C.T., Herrmann, M.G., Moss, A.A., and Rasmussen, R.P. (1997). Continuous fluorescence monitoring of rapid cycle DNA amplification. Biotechniques 22, 130-138.

Wittwer, C.T., Herrmann, M.G., Gundry, C.N., and ElenitobaJohnson, K.S. (2001). Real-time multiplex PCR assays. Methods 4, 430-442.

Yap, E.P.H., Lo, Y., Y.M.O., Fleming, K.A., and McGee, J.O.D. (1994). False-positives and contamination in PCR. Ed H.G. Griffin, A.M. Griffin (eds.). PCR Technology, current innovations, (Boca Raton, USA, CRC Press). 


\section{Further Reading}

Caister Academic Press is a leading academic publisher of advanced texts in microbiology, molecular biology and medical research. Full details of all our publications at caister.com

- MALDI-TOF Mass Spectrometry in Microbiology Edited by: M Kostrzewa, S Schubert (2016) www.caister.com/malditof

- Aspergillus and Penicillium in the Post-genomic Era Edited by: RP Vries, IB Gelber, MR Andersen (2016) www.caister.com/aspergillus2

- The Bacteriocins: Current Knowledge and Future Prospects Edited by: RL Dorit, SM Roy, MA Riley (2016)

www.caister.com/bacteriocins

- Omics in Plant Disease Resistance Edited by: V Bhadauria (2016) www.caister.com/opd

- Acidophiles: Life in Extremely Acidic Environments Edited by: R Quatrini, DB Johnson (2016) www.caister.com/acidophiles

- Climate Change and Microbial Ecology: Current Research and Future Trend

Edited by: J Marxsen (2016)

www.caister.com/climate

- Biofilms in Bioremediation: Current Research and Emerging Technologies

Edited by: G Lear (2016)

www.caister.com/biorem

- Microalgae: Current Research and Applications Edited by: MN Tsaloglou (2016) www.caister.com/microalgae

- Gas Plasma Sterilization in Microbiology: Theory, Applications, Pitfalls and New Perspectives Edited by: H Shintani, A Sakudo (2016) www.caister.com/gasplasma

- Virus Evolution: Current Research and Future Directions Edited by: SC Weaver, M Denison, M Roossinck, et al. (2016) www.caister.com/virusevol

- Arboviruses: Molecular Biology, Evolution and Control Edited by: N Vasilakis, DJ Gubler (2016) www.caister.com/arbo

- Shigella: Molecular and Cellular Biology Edited by: WD Picking, WL Picking (2016) www.caister.com/shigella

-Aquatic Biofilms: Ecology, Water Quality and Wastewater Treatment

Edited by: AM Romaní, H Guasch, MD Balaguer (2016)

www.caister.com/aquaticbiofilms

- Alphaviruses: Current Biology

Edited by: S Mahalingam, L Herrero, B Herring (2016)

www.caister.com/alpha

- Thermophilic Microorganisms

Edited by: F Li (2015)

www.caister.com/thermophile
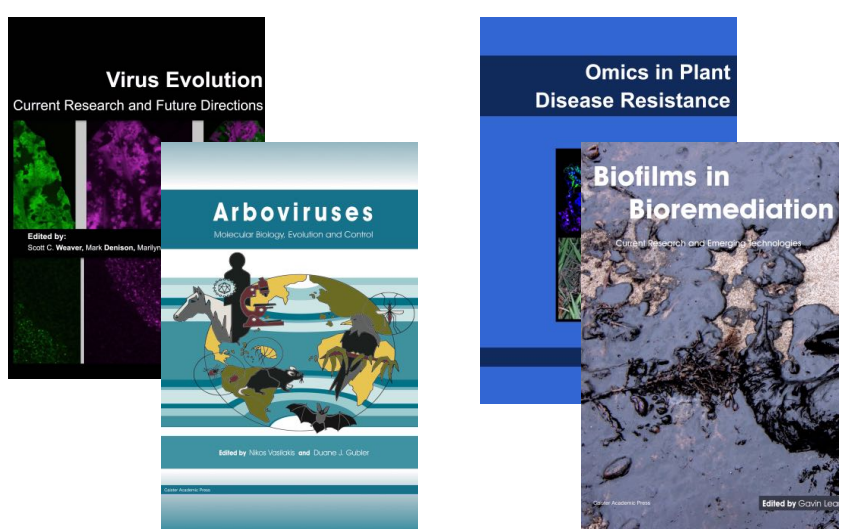
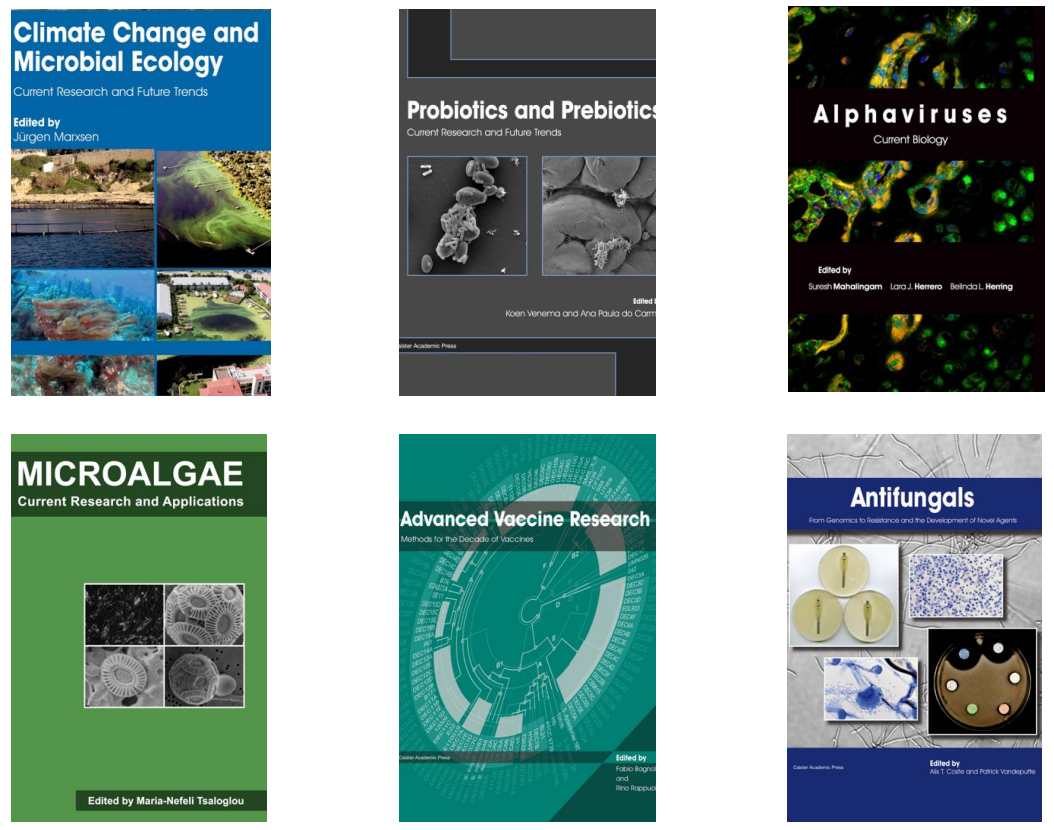

- Flow Cytometry in Microbiology: Technology and Applications Edited by: MG Wilkinson (2015) www.caister.com/flow

- Probiotics and Prebiotics: Current Research and Future Trends Edited by: K Venema, AP Carmo (2015) www.caister.com/probiotics

- Epigenetics: Current Research and Emerging Trends Edited by: BP Chadwick (2015) www.caister.com/epigenetics2015

- Corynebacterium glutamicum: From Systems Biology to Biotechnological Applications

Edited by: A Burkovski (2015)

www.caister.com/cory2

- Advanced Vaccine Research Methods for the Decade of Vaccines

Edited by: F Bagnoli, R Rappuoli (2015)

www.caister.com/vaccines

- Antifungals: From Genomics to Resistance and the Development of Novel Agents

Edited by: AT Coste, P Vandeputte (2015)

www.caister.com/antifungals

- Bacteria-Plant Interactions: Advanced Research and Future Trends Edited by: J Murillo, BA Vinatzer, RW Jackson, et al. (2015) www.caister.com/bacteria-plant

\section{- Aeromonas}

Edited by: J Graf (2015)

www.caister.com/aeromonas

- Antibiotics: Current Innovations and Future Trends

Edited by: S Sánchez, AL Demain (2015)

www.caister.com/antibiotics

- Leishmania: Current Biology and Contro Edited by: S Adak, R Datta (2015) www.caister.com/leish2

- Acanthamoeba: Biology and Pathogenesis (2nd edition) Author: NA Khan (2015)

www.caister.com/acanthamoeba2

- Microarrays: Current Technology, Innovations and Applications Edited by: Z He (2014)

www.caister.com/microarrays2

- Metagenomics of the Microbial Nitrogen Cycle: Theory, Methods and Applications

Edited by: D Marco (2014)

www.caister.com/n2 